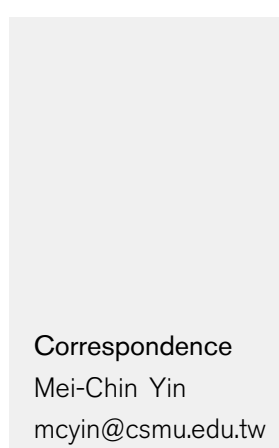

Received 22 February 2005

Accepted 22 November 2005

\section{Meticillin-resistant Staphylococcus aureus infection in diabetic mice enhanced inflammation and coagulation}

\author{
Shyh-Ming Tsao, ${ }^{1}$ Cheng-Chin Hsu ${ }^{2}$ and Mei-Chin Yin ${ }^{2}$
}

Department of Infection, Chung Shan Medical University Hospital, ${ }^{1}$ and Institute of Nutritional Science, Chung Shan Medical University, ${ }^{2}$ Taichung City, Taiwan, ROC

\section{INTRODUCTION}

Meticillin-resistant Staphylococcus aureus (MRSA) is a common nosocomial pathogen in Taiwan and other countries (Mattila et al., 1998; Jang et al., 1999). Healthcare-associated MRSA strains are resistant to many antibiotics (Hiramatsu et al., 1997; Chang et al., 2000), and MRSA infection markedly increases the morbidity and mortality in hospitalized patients. In our previous study we found that MRSA infection in nondiabetic BALB/cA mice resulted in MRSA distribution in the blood and organs, and elevated plasma levels of interleukin-6 (IL-6), an inflammation marker, and fibronectin, an endothelial injury marker (Tsao et al., 2003). However, there is a lack of in vivo information regarding the influence of MRSA infection on other indicators for inflammation or endothelial injury, such as C-reactive protein,

Abbreviations: IFN- $\gamma$, gamma interferon; IL, interleukin; MRSA, meticillinresistant Staphylococcus aureus; MSSA, meticillin-susceptible Staphylococcus aureus; p.i., post-infection; PVL, Panton-Valentine leukocidin; TNF- $\alpha$, tumour necrosis factor alpha; VWF, von Willebrand factor. fibrinogen and von Willebrand factor (VWF), in nondiabetic and diabetic mice.

Type I diabetes is an immunoinflammatory disease. Several studies have indicated that the balance of Th1 type cytokines, such as gamma interferon (IFN- $\gamma$ ) and tumour necrosis factor alpha (TNF- $\alpha$ ), and Th2 type cytokines, such as IL- 4 and IL-10, is altered in diabetics, and that both cytokine types are involved in the development of type I diabetes (Shimada et al., 1996; Muller et al., 2002). However, it has been documented that infection interfered with the balance of Th1/Th2 cytokines in nondiabetic mice also (Geiger et al., 2001; Gonzalez et al., 2003). It remains unclear whether infection, especially MRSA infection, in diabetic individuals affects the regulation of Th1 and Th2 cytokines. Furthermore, the blood coagulation system in diabetic individuals is predominant over the anticoagulation system (Juhan-Vague et al., 2002; Kain et al., 2003; Lapolla et al., 2003). It is also known that infection is associated with a risk of thromboembolic complications (Lowry, 1998; Leinonen \& Saikku, 2000). Therefore, there is a need for in vivo evidence to help 
elucidate the influence of the diabetes and MRSA infection interaction on haemostatic balance.

The purposes of this study were to investigate the influence of MRSA infection on pathogen distribution, inflammation, endothelial injury, cytokine profile and coagulation in diabetic mice. Meticillin-susceptible S. aureus (MSSA) was used for comparison. The production of haemolysins and genes encoding potential virulence factors, such as PantonValentine leukocidin (PVL) and enterotoxin, were also compared between MRSA and MSSA. The difference in these clinical signs between diabetic and nondiabetic BALB/cA mice was monitored for several time periods in order to provide novel information for further clinical application.

\section{METHODS}

Animals. Male BALB/cA mice (8-9 weeks old) were obtained from the National Laboratory Animal Center (Science Council, Taipei City, Taiwan). Mice with bodyweight at $24 \cdot 3 \pm 0.6 \mathrm{~g}$ were used in this study. Mice were housed on a $12 \mathrm{~h} \mathrm{light} / 12 \mathrm{~h}$ dark schedule, and fed with rat and mouse standard diet no. 1120 and water ad libitum. Use of the mice was reviewed and approved by the Chung Shan Medical University Animal Care Committee. To induce diabetes, the mice were treated with streptozotocin $[40 \mathrm{mg}(\mathrm{kg}$ bodyweight $)^{-1}$ in $0 \cdot 1 \mathrm{M}$ citrate buffer, $\mathrm{pH} 4 \cdot 5$ ] by intraperitoneal administration for 5 consecutive days. Blood glucose levels were monitored on days 2, 5 and 10 from the tail vein by using a onetouch blood glucose meter. Mice with fasting blood glucose levels over $300 \mathrm{mg} \mathrm{dl}^{-1}$ were defined as diabetic mice and used for this study.

Strains and survival rate. A total of 11 clinical MSSA isolates and 11 clinical MRSA isolates were obtained from patients with diabetes and renal dysfunction at Chung Shan Medical University Hospital from October 2003 to April 2004. All isolates were identified by Vitek (Vitek AMS; bioMérieux Vitek, USA) and API 20E (APIbioMérieux, France). Antibiotic resistance profiles using vancomycin, meticillin, penicillin, cefotaxime and tetracycline were determined by disc diffusion. The discs with antibiotics were purchased from Sigma. Discs were placed on the surface of Mueller-Hinton agar plates supplemented with $2 \% \mathrm{NaCl}$ and seeded with MSSA or MRSA. Inhibition zones were measured after $24 \mathrm{~h}$ incubation at $35^{\circ} \mathrm{C}$. Interpretation of resistance was based on the National Committee for Clinical Laboratory Standards criteria (National Committee for Clinical Laboratory Standards, 1999). The 11 MRSA isolates were susceptible to vancomycin and resistant to the other four test antibiotics. All cultures were routinely maintained on Mueller-Hinton agar plates at $25^{\circ} \mathrm{C}$ until used. Prior to infection, MSSA and MRSAs were diluted with PBS to $10^{7}, 10^{8}, 10^{9}, 10^{10}, 10^{11}$ and $10^{12}$ c.f.u. $\mathrm{ml}^{-1}$, which could give approximately $10^{6}-10^{11}$ c.f.u. per mouse in a volume of $200 \mu$ l. Twenty mice were used for each MSSA or MRSA concentration. The survival rate of nondiabetic and diabetic mice was measured at 2 days post-infection (p.i.).

Detection of genes for PVL (lukPV-1), enterotoxins (sea, seb) and haemolysins. Genomic DNA was extracted from MSSA and MRSA cultures grown on agar plates and used as a template for amplification. The presence of genes $l u k P V-1$, sea and seb was confirmed by PCR (Jaffe et al., 2000). Oligonucleotide primers were designed according to the published sequences of $l u k P V L-1$, sea and seb genes (GenBank accession nos X72700, M18970 and M11118). The primers for these three genes were $5^{\prime}$-ATC ATT AGG TAA AAT GTC TGG ACA TGA TCCA-3', 5'-GAA AAA AGT CTG AAT TGC AGG GAA CA- $3^{\prime}$ and $5^{\prime}$-ATT CTA TTA AGG ACA CTA AGT TAG
GGA-3', respectively. The production of haemolysins $(\alpha$ or $\beta$ ) was confirmed by the method described by Nilsson et al. (1999). Briefly, MRSA and MSSA were cultivated in Columbia broth (Difco) at $37^{\circ} \mathrm{C}$ for $10 \mathrm{~h}$. After centrifuging at $3000 \mathrm{~g}$, the supernatant was collected and tested against sheep erythrocytes.

Experimental design. Mice infected with MSSA or MRSA at $10^{7}$ $10^{8}$ c.f.u. $\mathrm{ml}^{-1}$ showed a $100 \%$ survival rate in both nondiabetic and diabetic groups. Thus, MSSA or MRSA at a concentration of $10^{8}$ c.f.u. $\mathrm{ml}^{-1}$ was used for the following infection experiments. Diabetic and nondiabetic mice were infected by injecting $200 \mu \mathrm{l}$ MSSA- or MRSA-PBS solution via the tail vein. After infection, mice were kept under standard laboratory conditions with free access to food and water. On the day before infection (defined as day 0 ), and on $2,4,7,9,11,14$ and 17 days p.i., 10 mice from each group were killed with carbon dioxide. Blood, liver, kidney and spleen were collected from each mouse. Plasma was separated from erythrocytes immediately after blood collection. Each $200 \mathrm{mg}$ of tissue was homogenized with $2 \mathrm{ml}$ PBS ( $\mathrm{pH} \mathrm{7 \cdot 2)}$ in a motor-driven Teflonglass homogenizer (Glas-Col). The filtrate was used for further analyses. Plasma glucose concentration $\left(\mathrm{mg} \mathrm{dl}^{-1}\right)$ was determined by a glucose HK kit (Sigma).

Culture. Serial dilutions from plasma and the filtrate from each organ at $100 \mu \mathrm{l}$ were cultured on Mueller-Hinton agar plates supplemented with $2 \% \mathrm{NaCl}$. After incubation for $24 \mathrm{~h}$ at $35^{\circ} \mathrm{C}$, colonies were counted and calculated as $\log _{10}$ c.f.u. $\mathrm{ml}^{-1}$ or $\log _{10}$ c.f.u. $\mathrm{g}^{-1}$.

Measurement of inflammation and endothelial injury markers. Plasma levels of C-reactive protein, fibrinogen, fibronectin and VWF were measured as inflammation and endothelial injury markers. C-reactive protein level $\left(\mu \mathrm{g} \mathrm{ml}^{-1}\right)$ was determined with a commercial ELISA kit (Anogen). Fibrinogen level ( $\mathrm{g} \mathrm{l}^{-1}$ ) was assayed by using a commercial kit (Iatroset Fbg; Iatron Laboratory) based on the principle of salting out. Fibronectin $\left(\mathrm{mg} \mathrm{ml}^{-1}\right)$ was assayed by rabbit anti-rat fibronectin antibody and quantified by solid phase immunoenzymic ELISA. VWF antigen levels were measured by an ELISA, using a rabbit anti-rat VWF polyclonal antibody (DAKO). The VWF level was expressed as relative percentages compared to normal pooled plasma.

Cytokine measurement. Plasma levels of IL-2, IL-4, IL-6, IL-10, TNF- $\alpha$ and IFN $-\gamma$ before infection and during the course of the infection were detected by ELISA using Cytoscreen immunoassay kits (BioSource International). Samples were run in duplicates according to the manufacturer's instructions. The sensitivity of the assay with the lowest limit was $5 \mathrm{pg} \mathrm{ml}^{-1}$ for IL-2, IL-4, IL-6 and IL-10, and $10 \mathrm{pg} \mathrm{ml}^{-1}$ for TNF- $\alpha$, IFN- $\gamma$.

Measurement of coagulation and anticoagulation factors. Coagulation factor, plasminogen activator inhibitor-1 (PAI-1), and anticoagulation factors, antithrombin III (AT-III) and protein C, were measured in this study. Blood samples were anticoagulated using sodium citrate according to the protocols provided by the manufacturers of the kits used. PAI-1 activity $\left(\mathrm{U} \mathrm{ml}^{-1}\right)$ was assayed by a commercial kit (Trinity Biotech). The activity (\%) of AT-III and protein $\mathrm{C}$ in plasma was determined by chromogenic assays according to the manufacturer's instructions using commercial ATIII and protein C kits (Sigma), and was shown as the ratio of those in normal human plasma.

Statistical analysis. A total of 11 clinical MSSA and MRSA isolates obtained from infected patients were used in this study. Data were expressed as mean \pm SD of 11 experiments $(n=11)$. Data were treated by one-way analysis of variance (ANOVA) and computed using the SAS general linear model procedure (SAS, 1990). Statistical significance was assayed by Student's $t$-test for unpaired data and differences were considered to be significant at $P<0 \cdot 05$. 
Table 1. Clinical features of mice before infection, and survival rate of mice infected with MSSA or MRSA at various concentrations

Data are means $\pm \mathrm{SD}(n=20)$.

\begin{tabular}{|lcc|}
\hline & Nondiabetic & Diabetic \\
\hline Clinical features & & \\
Bodyweight (g) & $26 \cdot 3 \pm 1 \cdot 6$ & $21 \cdot 0 \pm 1 \cdot 2^{*}$ \\
Liver weight (g) & $0 \cdot 731 \pm 0 \cdot 027$ & $0 \cdot 706 \pm 0 \cdot 031$ \\
Kidney weight (g) & $0 \cdot 142 \pm 0 \cdot 012$ & $0 \cdot 155 \pm 0 \cdot 021$ \\
Spleen weight (g) & $0 \cdot 096 \pm 0 \cdot 008$ & $0 \cdot 084 \pm 0 \cdot 014$ \\
Fasting glucose level (mg dl $\left.{ }^{-1}\right)$ & $105 \pm 13$ & $423 \pm 28^{*}$ \\
Survival rate for MSSA & & \\
$10^{11}$ & $95 \%$ & $90 \%$ \\
$10^{10}$ & $100 \%$ & $95 \%$ \\
$10^{9}$ & $100 \%$ & $100 \%$ \\
$10^{7}-10^{8}$ & $100 \%$ & $100 \%$ \\
Survival rate for MRSA & & \\
$10^{10}$ & $90 \%$ & $35 \%{ }^{*}$ \\
$10^{9}$ & $100 \%$ & $75 \%{ }^{*}$ \\
$10^{7}-10^{8}$ & $100 \%$ & $100 \%$ \\
\hline
\end{tabular}

${ }^{\star}$ Values are significantly different $(P<0 \cdot 05)$ from nondiabetic group.

\section{RESULTS}

The clinical signs and survival rate of mice infected with various MSSA and MRSA concentrations are shown in Table 1. Diabetic mice had significantly lower bodyweights and higher fasting glucose levels than nondiabetic mice before infection $(P<0 \cdot 05)$. The expressed rate of PVL ( lukPV-1), enterotoxins (sea, seb) and haemolysins $(\alpha, \beta)$ in MSSA and MRSA strains are presented in Table 2. The test MRSAs expressed more lukPV, sea and seb genes than MSSA. Similarly, the test MRSAs also produced more haemolysins $(\alpha, \beta$ or $\alpha$ and $\beta$ ) than the 11 test MSSAs.

The distribution of MSSA and MRSA in plasma and organs is presented in Fig. 1. MSSA infection did not cause death during the entire experimental period, and the level of this pathogen in plasma or organs reduced gradually after 11 days infection. MRSA-infected nondiabetic and diabetic

Table 2. Expression of genes encoding PVL (lukPV-1), enterotoxins (sea, seb) and haemolysins $(\alpha, \beta)$ in $11 \mathrm{MSSA}$ and 11 MRSA strains

\begin{tabular}{|lcc|}
\hline Gene & MSSA & MRSA \\
\hline lukPV-1 & $2 / 11$ & $9 / 11$ \\
sea only & $2 / 11$ & $3 / 11$ \\
seb only & $3 / 11$ & $1 / 11$ \\
sea and seb & $0 / 11$ & $7 / 11$ \\
Haemolysin $\alpha$ only & $1 / 11$ & $3 / 11$ \\
Haemolysin $\beta$ only & $2 / 11$ & $3 / 11$ \\
Haemolysin $\alpha$ and $\beta$ & $0 / 11$ & $5 / 11$ \\
\hline
\end{tabular}
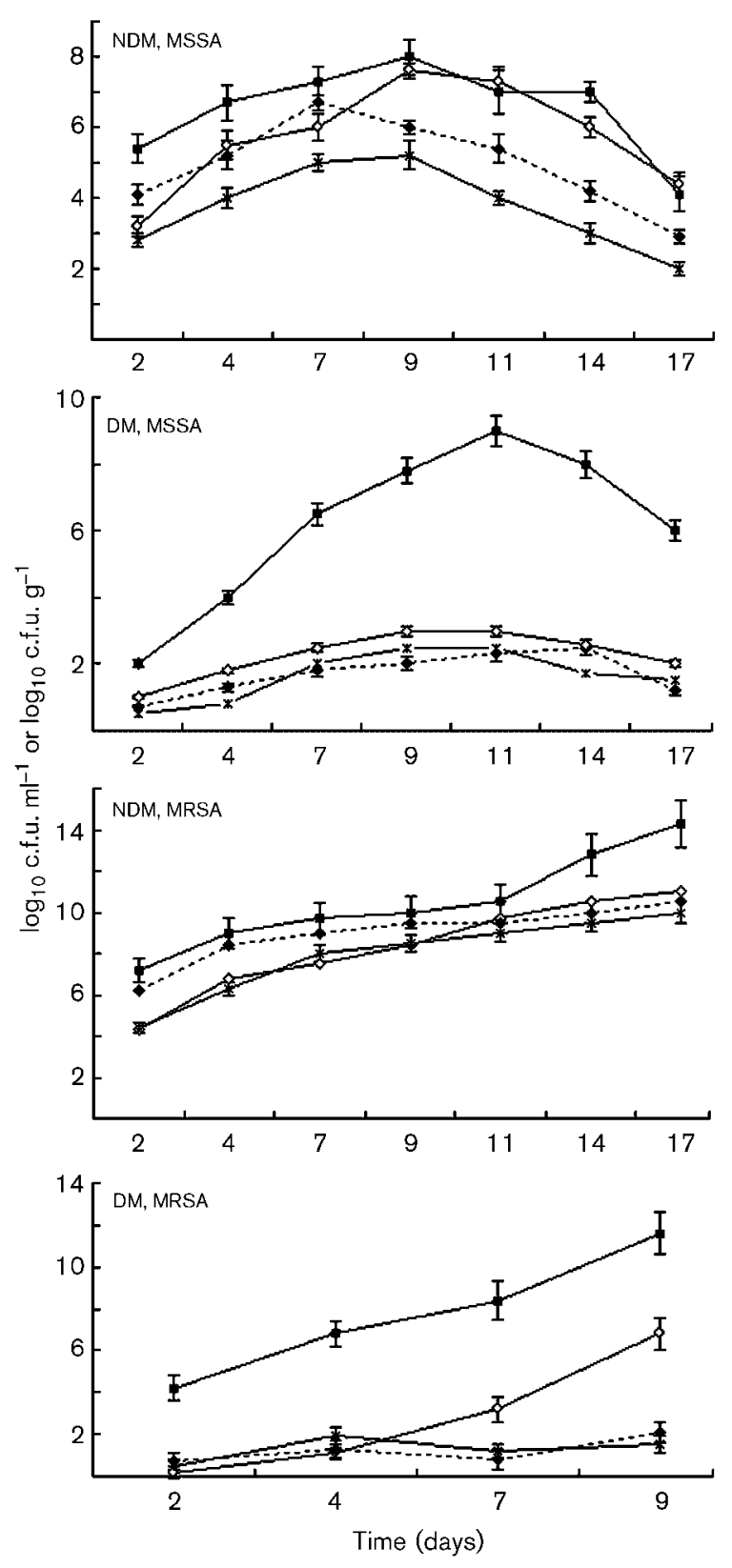

Fig. 1. MSSA or MRSA level in plasma $\left(\log _{10}\right.$ c.f.u. $\left.\mathrm{ml}^{-1}\right)$, and in liver, kidney and spleen $\left(\log _{10}\right.$ c.f.u. $\left.\mathrm{g}^{-1}\right)$ from nondiabetic (NDM) and diabetic (DM) mice. Data are means \pm SD $(n=11)$. $\diamond$, Plasma; $\diamond$, liver; $\mathbf{\square}$, kidney; X, spleen.

mice died on $19 \cdot 1 \pm 1 \cdot 4$ and $10 \cdot 6 \pm 0 \cdot 7$ days p.i., respectively. In nondiabetic mice, MSSA or MRSA was distributed in plasma, kidney, liver and spleen; however, the level of either MSSA or MRSA in diabetic mice was significantly increased only in kidney $(P<0 \cdot 05)$. Plasma glucose levels for diabetic or nondiabetic mice infected with MSSA or MRSA are presented in Fig. 2. MSSA infection did not significantly affect glucose level $(P>0 \cdot 05)$; however, MRSA infection in diabetic mice caused significant reduction in glucose level $(P<0 \cdot 05)$. 


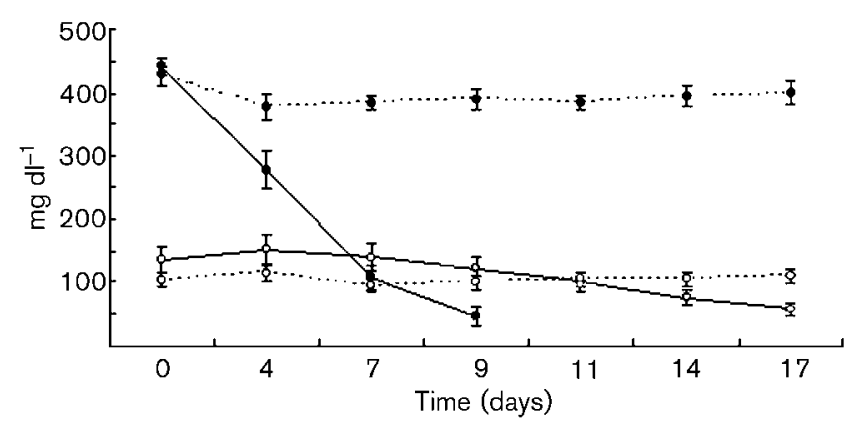

Fig. 2. Glucose level $\left(\mathrm{mg} \mathrm{dl}^{-1}\right)$ in plasma from nondiabetic $(\bigcirc)$ and diabetic (O) mice before (day 0) and after MSSA (dotted lines) or MRSA (continuous lines) infection. Data are means \pm SD $(n=11)$.

The blood markers of inflammation and endothelial injury are shown in Table 3. Diabetic mice showed significantly higher levels of C-reactive protein, fibrinogen, fibronectin and VWF than nondiabetic mice $(P<0 \cdot 05)$. MSSA infection resulted in a slight, but not significant, elevation in these markers in both nondiabetic and diabetic mice $(P>0 \cdot 05)$; however, MRSA infection caused a significant increase in these markers, especially in diabetic mice $(P<0 \cdot 05)$. The influence of diabetes and MRSA infection on coagulation and anticoagulation factors is presented in Table 4. Before infection, diabetic mice had significantly lower AT-III and protein $\mathrm{C}$ activities, and a higher PAI- 1 activity $(P<0 \cdot 05)$ than nondiabetic mice. MSSA infection did not further affect these coagulation and anticoagulation factors $(P>0 \cdot 05)$; however, MRSA infection in diabetic mice significantly reduced the activity of AT-III and protein C $(P<0.05)$ further, as well as significantly increasing PAI- 1 activity $(P<0 \cdot 05)$.

Plasma levels of Th1 and Th2 cytokines are presented in Figs 3 and 4. MRSA infection significantly increased the levels of three Th1 cytokines, IL-2, TNF- $\alpha$ and IFN- $\gamma$, and three Th2 cytokines, IL-4, IL- 6 and IL-10, in diabetic mice $(P<0 \cdot 05)$; however, the levels of Th 2 cytokines dropped at 7 and 9 days p.i.
Table 4. Activity of AT-III (\%), protein C (\%) and PAI-1 $\left(\mathrm{U} \mathrm{ml}^{-1}\right)$ in plasma from nondiabetic (NDM) and diabetic (DM) mice at day 0 (before infection) and days 4, 9, 14, 17 after MSSA or MRSA infection

Data are mean $\pm \mathrm{SD}(n=11)$.

\begin{tabular}{|c|c|c|c|c|}
\hline & \multicolumn{2}{|c|}{ MSSA } & \multicolumn{2}{|c|}{ MRSA } \\
\hline & NDM & DM & NDM & DM \\
\hline \multicolumn{5}{|c|}{ AT-III (\%) } \\
\hline Day 0 & $125 \pm 12$ & $97 \pm 5$ & $129 \pm 10$ & $98 \pm 8^{*}$ \\
\hline Day 4 & $120 \pm 10$ & $94 \pm 7$ & $85 \pm 6$ & $51 \pm 7^{\star}$ \\
\hline Day 9 & $118 \pm 13$ & $95 \pm 4$ & $78 \pm 4$ & $21 \pm 3^{*}$ \\
\hline Day 14 & $117 \pm 8$ & $96 \pm 8$ & $72 \pm 6$ & - \\
\hline Day 17 & $122 \pm 14$ & $95 \pm 5$ & $69 \pm 5$ & - \\
\hline \multicolumn{5}{|c|}{ Protein C (\%) } \\
\hline Day 0 & $96 \pm 8$ & $82 \pm 6$ & $94 \pm 6$ & $80 \pm 7^{*}$ \\
\hline Day 4 & $92 \pm 6$ & $85 \pm 3$ & $70 \pm 7$ & $44 \pm 5^{*}$ \\
\hline Day 9 & $95 \pm 7$ & $83 \pm 5$ & $59 \pm 9$ & $16 \pm 6^{*}$ \\
\hline Day 14 & $93 \pm 4$ & $82 \pm 7$ & $52 \pm 5$ & - \\
\hline Day 17 & $93 \pm 5$ & $85 \pm 4$ & $42 \pm 6$ & - \\
\hline \multicolumn{5}{|c|}{ PAI-1 $\left(\mathrm{U} \mathrm{ml}^{-1}\right)$} \\
\hline Day 0 & $7 \cdot 2 \pm 0 \cdot 6$ & $8 \cdot 6 \pm 0 \cdot 8$ & $7 \cdot 0 \pm 1 \cdot 1$ & $17 \cdot 6 \pm 1 \cdot 0^{*}$ \\
\hline Day 4 & $7 \cdot 3 \pm 0 \cdot 5$ & $8 \cdot 3 \pm 1 \cdot 0$ & $7 \cdot 5 \pm 1 \cdot 4$ & $18 \cdot 2 \pm 1 \cdot 4^{*}$ \\
\hline Day 9 & $7 \cdot 5 \pm 0 \cdot 7$ & $8 \cdot 7 \pm 0 \cdot 7$ & $8 \cdot 7 \pm 0 \cdot 9$ & $23 \cdot 9 \pm 2 \cdot 1^{\star}$ \\
\hline Day 14 & $7 \cdot 1 \pm 0 \cdot 5$ & $8 \cdot 1 \pm 0 \cdot 9$ & $9 \cdot 5 \pm 0 \cdot 7$ & - \\
\hline Day 17 & $7 \cdot 6 \pm 0 \cdot 4$ & $8 \cdot 4 \pm 1 \cdot 1$ & $10 \cdot 4 \pm 1 \cdot 2$ & - \\
\hline
\end{tabular}

*Values are significantly different $(P<0 \cdot 05)$ from MRSA-infected nondiabetic group.

\section{DISCUSSION}

The 11 MRSA isolates used produced markedly more haemolysins and harboured more genes encoding enterotoxins and PVL, a synergohymenotropic toxin. Thus, it is reasonable to observe severe infection, inflammation and coagulation in these MRSA-infected mice. Based on the lower survival rate and shorter survival length, diabetic mice were susceptible to MRSA infection. However, both MRSA and MSSA infection did not result in marked symptomatic bacteraemia in diabetic mice. Thus, cultures from blood

Table 3. Plasma levels of C-reactive protein, fibrinogen, fibronectin and VWF in nondiabetic (NDM) and diabetic (DM) mice at day 0 (before infection) and day 9 after MSSA or MRSA infection

Data are mean \pm SD $(n=11)$.

\begin{tabular}{|lcccc|}
\hline & $\begin{array}{c}\text { NDM MSSA, } \\
\text { day 0/day 9 }\end{array}$ & $\begin{array}{c}\text { DM MSSA, } \\
\text { day 0/day } \mathbf{9}\end{array}$ & $\begin{array}{c}\text { NDM MRSA, } \\
\text { day 0/day 9 }\end{array}$ & $\begin{array}{c}\text { DM MRSA, } \\
\text { day 0/day 9 }\end{array}$ \\
\hline C-reactive protein $\left(\mu \mathrm{g} \mathrm{ml}^{-1}\right)$ & $19 \cdot 5 \pm 1 \cdot 7 / 22 \cdot 3 \pm 2 \cdot 2$ & $29 \cdot 8 \pm 2 \cdot 7 / 33 \cdot 5 \pm 4 \cdot 1$ & $20 \cdot 2 \pm 1 \cdot 5 / 39 \cdot 6 \pm 3 \cdot 4^{*}$ & $31 \cdot 0 \pm 2 \cdot 5 / 66 \cdot 4 \pm 5 \cdot 8^{*}$ \\
Fibrinogen $\left(\mathrm{g} \mathrm{l}^{-1}\right)$ & $2 \cdot 25 \pm 0 \cdot 33 / 2 \cdot 31 \pm 0 \cdot 51$ & $4 \cdot 11 \pm 0 \cdot 50 / 4 \cdot 47 \pm 0 \cdot 61$ & $2 \cdot 17 \pm 0 \cdot 25 / 2 \cdot 94 \pm 0 \cdot 30^{*}$ & $4 \cdot 18 \pm 0 \cdot 44 / 7 \cdot 62 \pm 0 \cdot 72^{*}$ \\
Fibronectin $\left(\mathrm{mg} \mathrm{ml}^{-1}\right)$ & $2 \cdot 42 \pm 0 \cdot 28 / 2 \cdot 78 \pm 0 \cdot 30$ & $4 \cdot 08 \pm 0 \cdot 35 / 4 \cdot 66 \pm 0 \cdot 44$ & $2 \cdot 45 \pm 0 \cdot 31 / 3 \cdot 42 \pm 0 \cdot 28^{*}$ & $4 \cdot 15 \pm 0 \cdot 29 / 5 \cdot 96 \pm 0 \cdot 52^{\star}$ \\
VWF $(\%)$ & $34 \cdot 7 \pm 5 \cdot 7 / 38 \cdot 9 \pm 6 \cdot 1$ & $57 \cdot 3 \pm 6 \cdot 3 / 64 \cdot 2 \pm 7 \cdot 8$ & $33 \cdot 6 \pm 4 \cdot 9 / 73 \cdot 9 \pm 8 \cdot 2^{*}$ & $55 \cdot 9 \pm 7 \cdot 0 / 127 \cdot 2 \pm 10 \cdot 2^{*}$ \\
\hline
\end{tabular}

*Values are significantly different $(P<0 \cdot 05)$ from the same group at day 0 . 

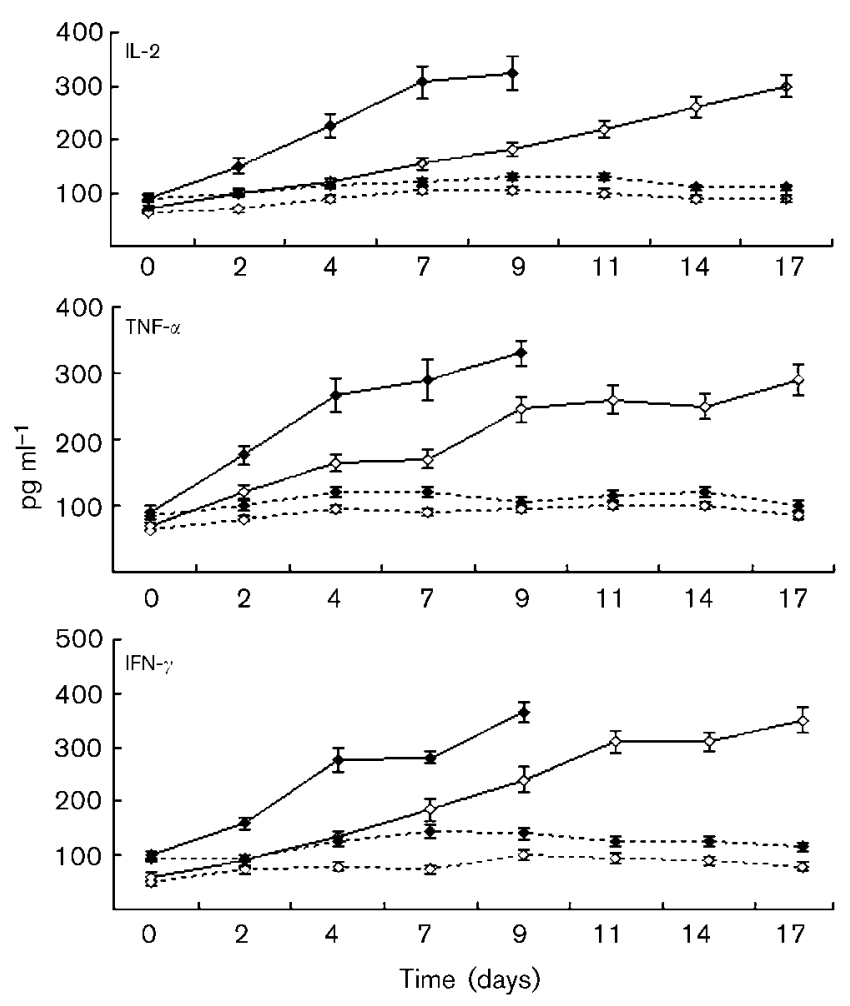

Fig. 3. Th1 cytokines (IL-2, TNF- $\alpha$, IFN- $\gamma$ ) in plasma from nondiabetic $(\diamond)$ and diabetic $(\diamond)$ mice after MSSA (dotted lines) or MRSA (continuous lines) infection. Data are means $\pm S D$ $(n=11)$.

(plasma or serum) may not be appropriate for detecting MRSA or MSSA infection in diabetic individuals. Therefore, other clinical diagnoses should be used for examining early infection in these individuals. Another novel finding from this study was that MRSA infection markedly decreased plasma glucose in diabetic mice. It has been reported that the TNF- $\alpha$ overproduction could cause hypoglycaemia in mice (Endo, 1991; Vogel et al., 1991). In our present study, a high plasma level of TNF- $\alpha$ was present in MRSA-infected diabetic mice, which may contribute to the observed hypoglycaemia.

Type I diabetes patients are characterized by elevated levels of C-reactive protein, fibrinogen, fibronectin and VWF; these endothelial-associated proteins are commonly used as indicators for inflammation and endothelial injury (Ciarla et al., 2001; Gomes et al., 2003; Aso et al., 2004). The results of our study agree with those of previous studies: diabetic induction increased the levels of these markers. Furthermore, our study found that MRSA infection in diabetic mice exacerbated the inflammation process and vascularendothelial dysfunction. Besides acting as inflammation or endothelial-injury markers, fibrinogen, fibronectin and VWF are also important adhesive and procoagulant proteins because these factors participate in atherosclerotic plaque thrombus formation and are involved in platelet
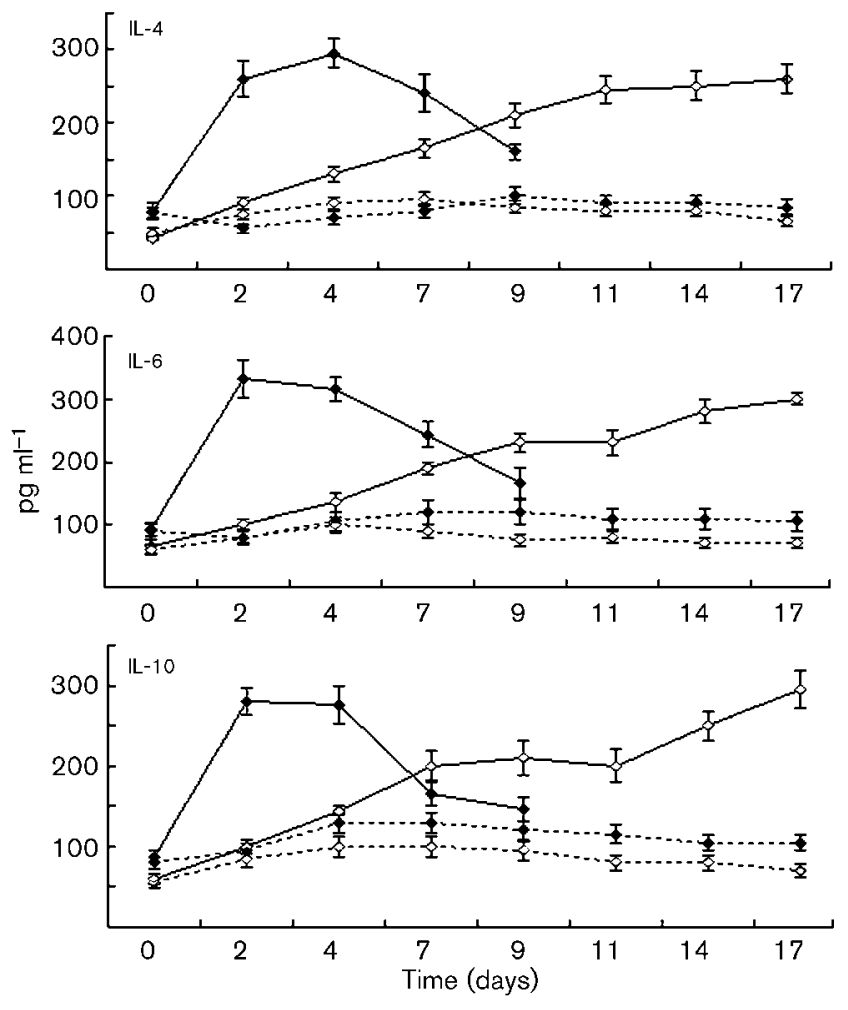

Fig. 4. Th2 cytokines (IL-4, IL-6, IL-10) in plasma from nondiabetic $(\diamond)$ and diabetic mice $(\diamond)$ after MSSA (dotted lines) or MRSA (continuous lines) infection. Data are means $\pm S D$ $(n=11)$.

dysfunction (Bennet \& Kolodziej, 1992; Mohamed-Ali et al., 2001). Thus, we believe that the increase of these blood markers in MRSA-infected diabetic mice accelerated coagulation progression. However, we also found the interaction of diabetes and MRSA infection resulted in markedly upregulated PAI-1 activity and down-regulated AT-III and protein $\mathrm{C}$ activities. It is known that PAI-1 is the primary physiological inhibitor of fibrinolysis (Urano et al., 2000), and AT-III and protein C are anticoagulation factors, because AT-III could inhibit the activity of a number of proteases in the coagulation cascade (Asakawa et al., 2000), and protein C could inactivate coagulation factors such as factors $\mathrm{Va}$ and VIIIa (Shen et al., 1997). Thus, these results also suggest that this interaction of diabetes and MRSA infection strongly impaired anticoagulation and fibrinolysis systems, and favoured the development of thrombosis and atherosclerosis. The affected haemostatic balance in these MRSA-infected mice may be partially due to the changed cytokine profiles. It has been shown that IFN- $\gamma$ and TNF- $\alpha$ could induce the synthesis of PAI-1, which up-regulated lymphoid-cellassociated procoagulant activity (Sakamoto et al., 1999; Urano et al., 2000), and IL-4 could induce the expression of anticoagulant protein S (Smiley et al., 1997). In our study, both an elevation in IFN- $\gamma$ and TNF- $\alpha$, and a reduction in IL-4 were observed in MRSA-infected diabetic mice, which might consequently enhance lymphoid-cell-associated 
coagulation by increasing PAI-1 synthesis, diminishing the protein S-related anticoagulant activity and impairing fibrinolytic activity.

The diabetes induced by low doses of streptozotocin is a $\mathrm{T}$ lymphocyte-dependent model. Several studies have indicated that both Th1 and Th2 cytokines are overexpressed during diabetic development in this model (Herold et al., 1996; Muller et al., 2002). In our present study, we also observed that diabetic induction caused a marked increase in both Th1 and Th2 cytokines (data not shown). Furthermore, we found MRSA infection further elevated Th1 cytokines in diabetic mice. These results suggest the interaction of MRSA infection and diabetes strongly stimulated the expression of Th1 cytokines. MRSA infection also upregulated Th2 cytokines in diabetic mice; however, this upregulation appeared at the early stage of infection ( 2 and 4 days p.i.) only. The dramatic decline of Th2 cytokines at the late stage was found in MRSA-infected diabetic mice only; thus, we believe it was definitely due to the interaction of MRSA infection and diabetes. This finding suggested that the concomitant rise of Th1 cytokines with the decline of Th2 cytokines in MRSA-infected diabetic individuals seemingly represented a deteriorative development. This information might be helpful for developing a clinical diagnosis to examine infection in the diabetic individual. However, MRSA infection in nondiabetic mice caused the overproduction of Th1 and Th2 cytokines, which definitely contributed to the increased release of proteins responsible for inflammation, endothelial injury and coagulation. Thus, MRSA-infected nondiabetic mice were also in danger of atherosclerosis and thrombus complications. However, without the impact of diabetes, these MRSA-infected nondiabetic mice had a longer survival time.

It has been indicated that proinflammatory cytokines, IL-6 and TNF- $\alpha$, were central mediators for the regulation of several biomarkers such as C-reactive protein and VWF (McCarty, 1999; Mohamed-Ali et al., 2001; Tomita et al., 2004), which consequently contributed to the progression of inflammation, endothelial dysfunction and coagulation. In our study, the interaction of MRSA infection and diabetes definitely caused an elevation of IL- 6 and TNF- $\alpha$ in the early stages ( 2 and 4 days p.i.); thus, the observed up-regulation of coagulation factors and markers for inflammation and endothelial injury at this stage could be explained. However, the IL- 6 level decreased while TNF- $\alpha$ and adhesive and procoagulant proteins still increased at the late stage (after 4 days p.i.). Does this result suggest IL-6 is less important than TNF- $\alpha$ in regulating these endothelial-associated proteins? Or is IL-6 an inducer for the acute-phase response only? The other question is why does increased TNF- $\alpha$ not cause IL- 6 elevation, since TNF- $\alpha$ could stimulate several tissues to release IL-6 (McCarty, 1999)? It seems that other factors and/or conditions are involved in the action of IL-6/ TNF- $\alpha$ in regulating endothelial-associated proteins in MRSAinfected diabetic individuals. Further studies are necessary to elucidate the related factors and their relationships.
In conclusion, MRSA infection did not result in marked symptomatic bacteraemia in diabetic mice. The interaction of diabetic pathogenesis and MRSA infection in BALB/cA mice changed the Th1 and Th2 cytokine profile, which further impaired glycaemic regulation. Furthermore, this interaction markedly enhanced the production of several adhesive and procoagulant proteins, which accelerated the inflammation process, endothelial injury and blood coagulation in diabetic mice. Therefore, the development of proper infection diagnosis and timely use of effective treatments for MRSA-infected diabetic individuals is important and necessary.

\section{REFERENCES}

Asakawa, H., Tokunaga, K. \& Kawakami, F. (2000). Elevation of fibrinogen and thrombin-antithrombin III complex levels of type 2 diabetes mellitus patients with retinopathy and nephropathy. J Diabetes Complications 14, 121-126.

Aso, Y., Okumura, K., Inoue, T., Matsutomo, R., Yoshida, N., Wakabayashi, S., Takebayashi, K. \& Inukai, T. (2004). Results of blood inflammatory markers are associated more strongly with toebrachial index than with ankle-brachial index in patients with type 2 diabetes. Diabetes Care 27, 1381-1386.

Bennett, J. S. \& Kolodziej, M. A. (1992). Disorders of platelet function. Dis Mon 38, 577-631.

Chang, S. C., Hsieh, W. C. \& Liu, C. (2000). High prevalence of antibiotic resistance of common pathogenic bacteria in Taiwan. Diag Microbiol Infect Dis 36, 107-112.

Ciarla, M. V., Bocciarelli, A., Di Gregorio, S., Tordi, A., Cotroneo, P., Marra, G., Ghirlanda, G. \& Strom, R. (2001). Autoantibodies and endothelial dysfunction in well-controlled, uncomplicated insulin dependent diabetes mellitus patients. Atherosclerosis 158, 241-246.

Endo, Y. (1991). Parallel relationship between the increase in serotonin in the liver and the hypoglycaemia induced in mice by interleukin-1 and tumour necrosis factor. Immunol Lett 27, 75-79.

Geiger, S. M., Abrahams-Sandi, E., Soboslay, P. T., Hoffmann, W. H., Pfaff, A. W., Graeff-Teixeira, C. \& Schulz-Key, H. (2001). Cellular immune responses and cytokine production in BALB/c and C57BL/6 mice during the acute phase of Angiostrongylus costaricensis infection. Acta Trop 80, 59-68.

Gomes, M. B., Piccirillo, L. J., Nogueira, V. G. \& Matos, H. J. (2003). Acute-phase proteins among patients with type 1 diabetes. Diabetes Metab 29, 405-411.

Gonzalez, A., Sahaza, J. H., Ortiz, B. L., Restrepo, A. \& Cano, L. E. (2003). Production of pro-inflammatory cytokines during the early stages of experimental Paracoccidioides brasiliensis infection. Med Mycol 41, 391-399.

Herold, K. C., Vezys, V., Sun, Q., Viktora, D., Seung, E., Reiner, S. \& Brown, D. R. (1996). Regulation of cytokine production during development of autoimmune diabetes induced with multiple low doses of streptozotocin. J Immunol 156, 3521-3527.

Hiramatsu, K., Hanaki, H. \& Ino, T. (1997). Methicillin-resistant Staphylococcus aureus clinical strain with reduced vancomycin susceptibility. J Antimicrob Chemother 40, 135-136.

Jaffe, R. I., Lane, J. D., Albury, S. V. \& Niemeyer, D. M. (2000). Rapid extraction from and direct identification in clinical samples of methicillin-resistant staphylococci using PCR. J Clin Microbiol 38, 3407-3412. 
Jang, T. N., Kuo, B. I. \& Shen, S. H. (1999). Nosocomial gramnegative bacteria in critically ill patients: epidemiologic characteristics and prognostic factors in 147 episodes. J Formos Med Assoc 98 465-473.

Juhan-Vague, I., Morange, P. E. \& Alessi, M. C. (2002). The insulin resistance syndrome: implications for thrombosis and cardiovascular disease. Pathophysiol Haemost Thromb 32, 269-273.

Kain, K., Catto, A. J. \& Grant, P. J. (2003). Associations between insulin resistance and thrombotic risk factors in high-risk South Asian subjects. Diabet Med 20, 651-655.

Lapolla, A., Piarulli, F., Sartore, G., Rossetti, C., Martano, L., Carraro, P., De Paoli, M. \& Fedele, D. (2003). Peripheral artery disease in type 2 diabetes: the role of fibrinolysis. Thromb Haemost 89, 91-96.

Leinonen, M. \& Saikku, P. (2000). Infections and atherosclerosis. Scand Cardiovasc J 34, 12-20.

Lowry, F. D. (1998). Staphylococcus aureus infections. N Engl J Med 20, 520-532.

Mattila, K. J., Valtonen, V. V., Nieminen, M. S. \& Asikainen, S. (1998). Role of infection as a risk factor for atherosclerosis, myocardial infarction, and stroke. Clin Infect Dis 26, 719-734.

McCarty, M. F. (1999). Interleukin-6 as a central mediator of cardiovascular risk associated with chronic inflammation, smoking, diabetes and visceral obesity: down-regulation with essential fatty acids, ethanol and pentoxifylline. Med Hypotheses 52, 465-477.

Mohamed-Ali, V., Armstrong, L., Vlark, D., Bolton, C. H. \& Pinkney, J. H. (2001). Evidence for the regulation of levels of plasma adhesion molecules by proinflammatory cytokines and their soluble receptors in type 1 diabetes. J Intern Med 250, 415-421.

Muller, A., Schott-Ohly, P. \& Dohle, C. (2002). Differential regulation of Th1-type and Th2-type cytokine profiles in pancreatic islets of C57BL/6 and BALA/c mice by multiple low doses of streptozotocin. Immunobiology 205, 35-50.

National Committee for Clinical Laboratory Standards (1999). Performance Standards for Antimicrobial Susceptibility Testing. Ninth informational supplement, M100-S9. Villanova, PA: National Committee for Clinical Laboratory Standards.

Nilsson, I.-M., Hartford, O., Foster, T. \& Tarkowski, A. (1999). Alphatoxin and gamma-toxin jointly promote Staphylococcus aureus virulence in murine septic arthritis. Infect Immun 67, 1045-1049.

Sakamoto, T., Woodcock-Mitchell, J., Marutsuka, K., Mitchell, J. J., Sobel, B. E. \& Fujii, S. (1999). TNF- $\alpha$ and insulin, alone and synergistically, induce plasminogen activator inhibitor-1 expression in adipocytes. Am J Physiol Cell Physiol 276, C1391-C1397.

SAS (1990). SAS User's Guide: Statistics. Cary, NC: SAS Institute.

Shen, L., He, X. \& Dahlback, B. (1997). Synergistic cofactor function of factor $\mathrm{V}$ and protein $\mathrm{S}$ to activated protein $\mathrm{C}$ in the inactivation of the factor VIIIa-factor IXa complex - species specific interactions of components of the protein $\mathrm{C}$ anticoagulant system. Thromb Haemost 78, 1030-1036.

Shimada, A., Charlton, B., Rohane, P., Taylor-Edwards, C. \& Fathman, C. G. (1996). Immune regulation in type 1 diabetes. J Autoimmun 9, 263-269.

Smiley, S. T., Stitt, T. N. \& Grusby, M. J. (1997). Cross-linking of protein $S$ bound to lymphocytes promotes aggregation and inhibits proliferation. Cell Immunol 181, 120-126.

Tomita, M., Dragoman, M., Worcester, H., Conran, P. \& Santoro, T. J. (2004). Proinflammatory cytokine genes are constitutively overexpressed in the heart in experimental systemic lupus erythematosus: a brief communication. Exp Biol Med 229, 971-976.

Tsao, S.-M., Hsu, C.-C. \& Yin, M.-C. (2003). Garlic extract and two diallyl sulphides inhibit methicillin-resistant Staphylococcus aureus infection in BALB/cA mice. J Antimicrob Chemother 52, 974-980.

Urano, T., Ihara, H., Suzuki, Y., Takada, Y. \& Takada, A. (2000). Coagulation-associated enhancement of fibrinolytic activity via a neutralization of PAI-1 activity. Semin Thromb Hemost 26, 39-42.

Vogel, S. N., Henricson, B. E. \& Neta, R. (1991). Roles of interleukin1 and tumor necrosis factor in lipopolysaccharide-induced hypoglycemia. Infect Immun 59, 2494-2498. 